\title{
Article
}

\section{CYP2C19 Polymorphisms in Indonesia: Comparison among Ethnicities and the Association with Clinical Outcomes}

\author{
Muhammad Miftahussurur ${ }^{1,2, *, \dagger}$, Dalla Doohan ${ }^{2,3,+} \mathbb{0}$, Ari Fahrial Syam ${ }^{4}$, Iswan Abbas Nusi ${ }^{1}$, \\ Phawinee Subsomwong ${ }^{3,5}$, Langgeng Agung Waskito ${ }^{2,3}$, Hasan Maulahela ${ }^{4}$, Fardah Akil ${ }^{6}(\mathbb{D}$, \\ Willy Brodus Uwan ${ }^{7}$, Gontar Siregar ${ }^{8}$, Kartika Afrida Fauzia 2,3(1), Yudith Annisa Ayu Rezkitha ${ }^{2,9}$, \\ Abdul Rahman ${ }^{10}$, I Dewa Nyoman Wibawa ${ }^{11}$, Alexander Michael Joseph Saudale ${ }^{12}$, Marselino Richardo ${ }^{13}$, \\ Titong Sugihartono ${ }^{1}$, Alvi Chomariyati ${ }^{1}$, Taufan Bramantoro ${ }^{14}$, Tomohisa Uchida ${ }^{15}$ \\ and Yoshio Yamaoka 1,3,16,17,*(D)
}

check for updates

Citation: Miftahussurur, M.; Doohan, D.; Syam, A.F.; Nusi, I.A.; Subsomwong, P.; Waskito, L.A.; Maulahela, H.; Akil, F.; Uwan, W.B.; Siregar, G.; et al. CYP2C19 Polymorphisms in Indonesia: Comparison among Ethnicities and the Association with Clinical Outcomes. Biology 2021, 10, 300. https://doi.org/10.3390/ biology10040300

Received: 15 March 2021 Accepted: 30 March 2021 Published: 6 April 2021

Publisher's Note: MDPI stays neutral with regard to jurisdictional claims in published maps and institutional affiliations.

Copyright: (c) 2021 by the authors. Licensee MDPI, Basel, Switzerland. This article is an open access article distributed under the terms and conditions of the Creative Commons Attribution (CC BY) license (https:/ / creativecommons.org/licenses/by/ $4.0 /)$.
1 Gastroentero-Hepatology Division, Department of Internal Medicine, Faculty of Medicine-Dr. Soetomo Teaching Hospital, Universitas Airlangga, Surabaya 60286, Indonesia; iswan-a-n@fk.unair.ac.id (I.A.N.); titong.sugihartono@fk.unair.ac.id (T.S.); alvi.chomariyati-2017@fk.unair.ac.id (A.C.)

2 Institute of Tropical Disease, Universitas Airlangga, Surabaya 60115, Indonesia; doctordoohan@gmail.com (D.D.); langgengaw@gmail.com (L.A.W.); kartikafauzia@gmail.com (K.A.F.); yudithannisaayu@gmail.com (Y.A.A.R.)

3 Department of Environmental and Preventive Medicine, Oita University Faculty of Medicine, Yufu 879-5593, Japan; phawinee@oita-u.ac.jp

4 Division of Gastroenterology, Department of Internal Medicine, Faculty of Medicine, University of Indonesia, Jakarta 10430, Indonesia; ari_syam@hotmail.com (A.F.S.); hasan.maulahela@yahoo.com (H.M.)

5 Department of Microbiology and Immunology, Hirosaki University Graduate School of Medicine, Hirosaki, Aomori 036-8562, Japan

6 Center of Gastroentero-Hepatology, Department of Internal Medicine, Faculty of Medicine, Hasanuddin University, Makassar 90245, Indonesia; dndakil@gmail.com

7 Department of Internal Medicine, Santo Antonius Hospital, Pontianak 78243, Indonesia; uwan.willyb@gmail.com

8 Division of Gastroentero-Hepatology, Department of Internal Medicine, Faculty of Medicine, University of Sumatra Utara, Medan 20155, Indonesia; gontarsiregar@gmail.com

9 Faculty of Medicine, University of Muhammadiyah Surabaya, Surabaya 60113, Indonesia

10 Department of Internal Medicine, Kolaka General Hospital, Kolaka 93511, Indonesia; arahman22272@gmail.com

11 Division of Gastroentero-Hepatology, Department of Internal Medicine, Faculty of Medicine, University of Udayana, Denpasar 80232, Indonesia; agusbobwibawa@yahoo.com

12 Department of Internal Medicine, Prof. Dr. W. Z. Johannes General Hospital, Kupang 85111, Indonesia; alexsaudale10@gmail.com

13 Department of Internal Medicine, Merauke City General Hospital, Merauke 99613, Indonesia; marselino_richardo@yahoo.com

14 Department of Dental Public Health, Faculty of Dental Medicine, Universitas Airlangga, Surabaya 60131, Indonesia; taufan-b@fkg.unair.ac.id

15 Department of Molecular Pathology, Oita University Faculty of Medicine, Yufu 879-5593, Japan; tomohisa@oita-u.ac.jp

16 Global Oita Medical Advanced Research Center for Health, Oita University, Yufu 879-5593, Japan

17 Department of Gastroenterology and Hepatology, Baylor College of Medicine, Houston, TX 77030, USA

* Correspondence: muhammad-m@fk.unair.ac.id (M.M.); yyamaoka@oita-u.ac.jp (Y.Y.); Tel./Fax: +6231-502-3865 (M.M.); Tel.: +81-97-586-5740 (Y.Y.); Fax: +81-97-586-5749 (Y.Y.)

$+\quad$ These authors contributed equally to this work.

Simple Summary: CYP2C19 is known as an enzyme primarily responsible for metabolizing various drugs, such as proton pump inhibitor, antiplatelet, anti-epileptic, and anticoagulant. CYP2C19 is known to be polymorphic and can result in the clinical efficacy of drugs. To examine the prevalence and the distribution of the CYP2C19 genetic polymorphisms in Indonesia, we performed polymerase chain reaction-restriction fragment length polymorphism to the genomic DNA of Indonesian participants. In addition, we also analyzed the distribution of CYP2C19 polymorphisms among ethnicities and clinical outcomes. We found that the prevalence of intermediate metabolizers were the highest in Indonesia, followed by rapid metabolizers and poor metabolizers, respectively. The distribution 
of metabolizer groups were different between ethnic groups in Indonesia. Therefore, dosage adjustment should be considered when administering drugs-affected by CYP2C19 in Indonesia. The results presented in this study showed the distribution of CYP2C19 variant alleles at the population level in Indonesia and might be used as a consideration for providing personalized treatment in clinical practice.

Abstract: CYP2C19 polymorphisms are important factors for proton pump inhibitor-based therapy. We examined the CYP2C19 genotypes and analyzed the distribution among ethnicities and clinical outcomes in Indonesia. We employed the polymerase chain reaction-restriction fragment length polymorphism method to determine the CYP2C19 genotypes and evaluated inflammation severity with the updated Sydney system. For CYP2C19*2, 46.4\% were the homozygous wild-type allele, $14.5 \%$ were the homozygous mutated allele, and $39.2 \%$ were the heterozygous allele. For CYP2C19*3, $88.6 \%$ were the homozygous wild-type allele, $2.4 \%$ were the homozygous mutated allele, and $9.0 \%$ were the heterozygous allele. Overall, the prevalence of rapid, intermediate, and poor metabolizers in Indonesia was 38.5, 41.6, and 19.9\%, respectively. In the poor metabolizer group, the frequency of allele $* 2(78.8 \%)$ was higher than the frequency of allele *3 $(21.2 \%)$. The Papuan had a significantly higher likelihood of possessing poor metabolizers than the Balinese (OR 11.0; $\mathrm{P}=0.002)$. The prevalence of poor metabolizers was lower compared with the rapid and intermediate metabolizers among patients with gastritis and gastroesophageal reflux disease. Intermediate metabolizers had the highest prevalence, followed by rapid metabolizers and poor metabolizers. Dosage adjustment should therefore be considered when administering proton pump inhibitor-based therapy in Indonesia.

Keywords: H. pylori; gastritis; CYP2C19; polymorphism; infectious disease

\section{Introduction}

Triple therapy consisting of two antibiotics, such as amoxicillin and clarithromycin, accompanied by a proton pump inhibitor (PPI) is widely employed for the eradication therapy of Helicobacter pylori infection [1-4], an eradication that can reduce gastric mucosal inflammation, and show improvement in chronic gastritis [4-7]. PPIs increase H. pylori sensitivity to the effects of antibiotics by raising the intragastric $\mathrm{pH}$ to near neutral levels [8] and by increasing the intragastric concentration of antibiotics by decreasing antibiotic decay in digestive fluids $[8,9]$. There is consensus that PPI is an important drug for first-, second-, and even third-line therapy for H. pylori eradication $[1,4]$.

PPI is an acid-activated prodrug that is inactive in its native form [10] and is mainly metabolized in the liver. CYP2C19 is an enzyme primarily responsible for metabolizing most PPIs, including omeprazole, esomeprazole, lansoprazole, and pantoprazole [8], with the exception of rabeprazole, which is primarily metabolized by non-enzymatic reduction to form thioether [9]. CYP2C19 plays an important role in converting these PPIs into hydroxyl compounds through aromatic hydroxylation reactions before finally being metabolized by CYP3A4 into sulfone $[8,9,11]$.

The CYP2C19 gene contains nine exons and is located in chromosome 10 (10q24.110q24.3) [8]. The protein is expressed mainly in the liver and, to a lesser degree, in the intestinal wall. CYP2C19 is known to be polymorphic and presents 19 variants [11]. CYP2C19 most frequently shows two types of mutated alleles: CYP2C19*2 and CYP2C19*3. The most common mutation of CYP2C19*2 contains a single base $\mathrm{G}$ to A mutation at position 681 in exon 5, a mutation that produces splicing and changes the open reading frame, generating an early stop codon and a truncated protein. CYP2C19*3 contains a single base $\mathrm{G}$ to $\mathrm{A}$ mutation at position 636 in exon 4 , which also consequently generates an early stop codon and a truncated protein $[9,12]$.

Genetic polymorphisms of CYP2C19 can result in differing pharmacokinetics, pharmacodynamics, and consequently differences in the clinical efficacy of PPIs [13-15]. According to their CYP2C19 genotype differences, individuals can be characterized into three 
metabolic types: rapid, intermediate, and poor metabolizers. Rapid metabolizers are characterized by having two wild-type alleles and rapid enzyme activity, whereas poor metabolizers are characterized by two mutant alleles and an extremely slow rate of enzyme activity. The intermediate metabolizer is characterized by one wild-type and one mutant allele and, therefore, tends to have a moderate rate of enzyme activity. Although forming mostly a minority group, the poor metabolizer phenotype shows wide inter-ethnic differences between populations (13-20\% for the Japanese [16-18], 10.4\% for Thais [19], 11-15\% for the Chinese [14,20], 2-5\% for Europeans [21-23], and 9\% for Egyptians [24]). This phenotype might therefore have wide differences in terms of drug metabolism among ethnicities. Several studies have been conducted on the effect of the CYP2C19 genotype on curing $H$. pylori infection in various populations. This defect directly affects enzyme activity and consequently influences the efficacy of therapy. Due to its importance, dosing guidelines for drugs such as clopidogrel, tricyclic antidepressants, and selective serotonin-reuptake inhibitors have been established based on CYP2C19 genotypes [25-28]. Identifying the genetic variation of $\mathrm{CYP} 2 \mathrm{C} 19$ is an important factor in the dose adjustment for PPIs and might therefore improve the eradication rate.

Indonesia is an archipelago country in Southeast Asia, between the Indian and Pacific oceans, with more than 13,000 islands populated by over 261 million people consisting of hundreds of native ethnic groups. A study in Indonesia reported CYP2C19 polymorphism but evaluated CYP2C19*17 and only included one ethnicity (Bugis) as the participants [29]. Therefore, the CYP2C19*2 and CYP2C19*3 polymorphism variants present in the other ethnicities in Indonesia remain undiscovered. In addition, dyspepsia was the sixth and fifth most prevalent disease in Indonesian outpatients and inpatients, respectively [30]. Genotyping CYP2C19 polymorphisms could be an important consideration when deciding on PPI therapeutic doses and for reducing dyspeptic symptoms. In this study, we examined the prevalence of the CYP2C19*2 and CYP2C19*3 genetic polymorphisms in Indonesia. We also analyzed the distribution among ethnicities and clinical outcomes.

\section{Materials and Methods}

\subsection{Study Participants}

We used 784 samples from our previous nationwide studies in Indonesia conducted from January 2014 to September 2016 [31], as well as the diagnosis of various gastroduodenal diseases and gastric mucosal histological data. We randomly selected 166 participants based on ethnic groups and location, regardless of the result of the $H$. pylori infection status. The sample included Javanese (28 samples), Batak (27 samples), Bugis ( 37 samples), Chinese Indonesian (17 samples), Balinese (25 samples), Dayak (10 samples), Papuan (14 samples), and Timorese (8 samples). Upper endoscopies were performed and biopsies were taken for the histology and DNA analysis. Figure 1 shows the systematic flow of methods and analyses in this study. The study protocol was approved by the Ethics Committee of Dr. Soetomo Teaching Hospital (Surabaya, Indonesia), Dr. Cipto Mangunkusumo Teaching Hospital (Jakarta, Indonesia), Dr. Wahidin Sudirohusodo Teaching Hospital (Makassar, Indonesia), and Oita University Faculty of Medicine (Yufu, Japan). The study's protocol followed the principles of the 2013 Declaration of Helsinki. 


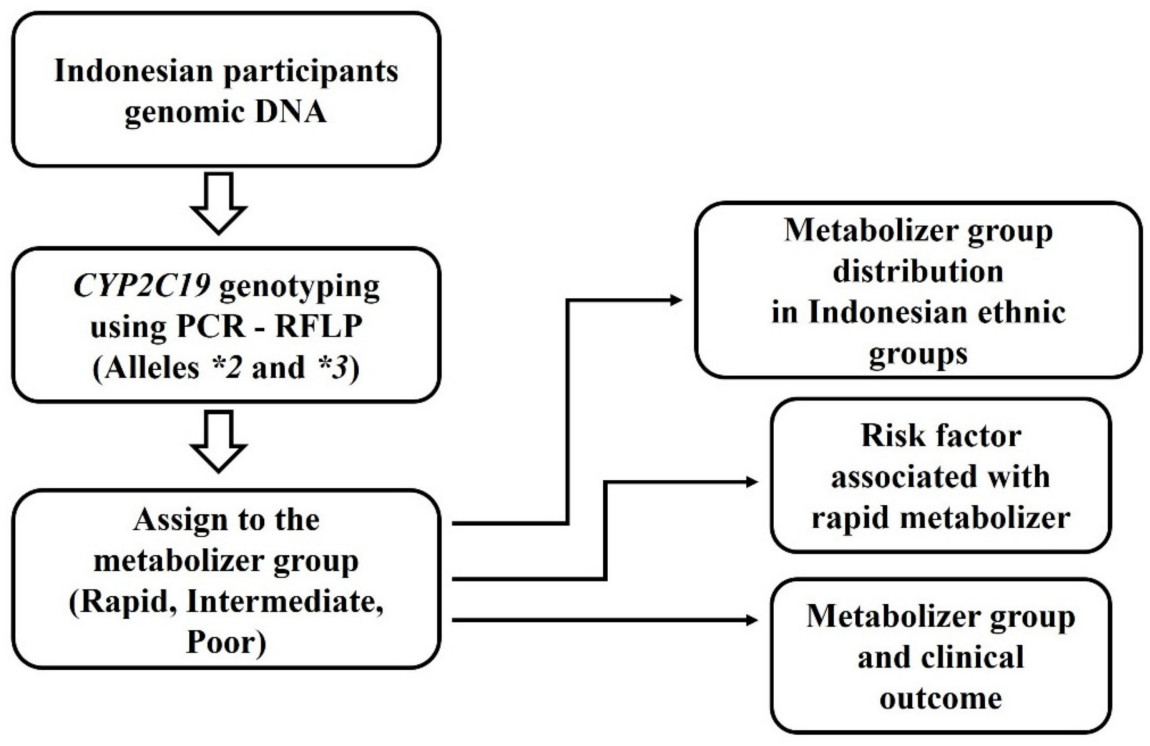

Figure 1. The systematic flow of methods and analyses in this study.

\subsection{Endoscopy Diagnosis and Gastritis Severity Score}

Clinical outcomes were obtained from the endoscopy diagnosis and gastritis severity scores by histology examination. The endoscopy diagnosis was reached based on the observations of the attending gastroenterologist and classified into gastritis, gastric ulcer, duodenal ulcer, and gastroesophageal reflux disease.

Gastric biopsy specimens were prepared and examined by the same pathologist (TU). Briefly, the paraffin-embedded biopsy was sliced and stained with hematoxylineosin and May-Giemsa staining. The inflammation severity was evaluated with a score of 0 (normal), 1 (mild), 2 (moderate), or 3 (marked) according to the updated Sydney system [32]. Antrum-predominant or corpus-predominant gastritis was determined if the total of the acute (neutrophil) and chronic (monocyte) inflammatory scores was higher in the antrum or corpus, respectively [33].

\subsection{CYP2C19 Polymorphism Genotyping}

For the genomic DNA isolation, we employed $150 \mu \mathrm{L}$ of gastric homogenate extracted using the DNeasy Blood and Tissue Kit (Qiagen, Germany) according to the manufacturer's instructions. We evaluated the CYP2C19*2 (rs4244285; 681G >A and CYP2C19*3 (rs4986893; $636 \mathrm{G}>\mathrm{A}$ ) by polymerase chain reaction (PCR)-restriction fragment length polymorphism. We employed genomic DNA as a template with specific primers and conditions, as previously described [16,34]. Amplification of CYP2C19*2 resulted in a $168 \mathrm{bp}$ band, and amplification of $C Y P 2 C 19 * 3$ resulted in a $119 \mathrm{bp}$ band. The amplified PCR products of CYP2C19*2 and *3 were digested with SmaI restriction enzyme (New England Biolabs, Tokyo, Japan) for $1 \mathrm{~h}$ at $25^{\circ} \mathrm{C}$ and BamHI restriction enzyme (Takara, Tokyo, Japan) for $1 \mathrm{~h}$ at $30^{\circ} \mathrm{C}$, respectively. The digested product was checked by agarose gel electrophoresis stained with ethidium bromide. Given that the restriction site is absent in the mutated alleles, the PCR products are not digested by the enzyme.

\subsection{Classification of CYP2C19 Genotype Groups}

Based on the $C Y P 2 C 19 * 2$ genotyping results, we categorized the patients into three different genotypes: wild-type allele $\left({ }^{*} 1 /{ }^{*} 1\right)$, homozygous for the mutated allele $\left({ }^{*} 2 /{ }^{*} 2\right)$, and heterozygous for the mutated allele $\left({ }^{*} 1 /{ }^{*} 2\right)$, and for the CYP2C19*3 polymorphism, we categorized the patients into three genotypes: wild-type allele $\left({ }^{*} 1 /{ }^{*} 1\right)$, homozygous for the mutated allele $\left({ }^{*} 3 /{ }^{*}\right)$, and heterozygous for the mutated allele $\left({ }^{*} 1 /{ }^{*}\right)$. Based on the combination of CYP2C19 polymorphism genotyping in exons 5 and 4 , the enzymatic activity associated with CYP2C19 genotypes was classified into three groups: rapid metabolizer, 
intermediate metabolizer, and poor metabolizer. Homozygous wild-type alleles $\left({ }^{*} 1 /{ }^{*} 1\right)$ in both exons were regarded as rapid metabolizers. Heterozygous allele in one exon $\left({ }^{*} 1 /{ }^{*} 2\right.$ or $\left.{ }^{*} 1 /{ }^{*} 3\right)$ while the other exon being wild-type allele was regarded as intermediate metabolizers. Homozygous mutant allele in one exon $\left({ }^{*} 2 /{ }^{*} 2\right.$ or $\left.* 3 /{ }^{*}\right)$ while the other exon being wild-type allele was regarded as poor metabolizers. Individual with a mutation in both exon 5 and exon $4\left({ }^{*} /{ }^{*} 2\right.$ and ${ }^{*} 1 /{ }^{*} 3$ genotypes, ${ }^{*} 1 /{ }^{*} 2$ and ${ }^{*} 3 /{ }^{*} 3$ genotypes, or ${ }^{*} 1 /{ }^{*} 2$ and ${ }^{*} 1 /{ }^{*} 3$ genotypes) was assigned as heterozygous $\left({ }^{*} 2 /{ }^{*}\right)$ and also regarded as a poor metabolizers.

\subsection{Statistical Analysis}

The statistical analysis was performed using SPSS version 23 (IBM Corp., Armonk, NY, USA). The significance of the difference in CYP2C19 genotypes between ethnicities was analyzed using the chi-squared test or Fisher's exact test. The odds ratios (ORs) with 95\% confidence intervals (CIs) were calculated using a logistic regression model. A P-value $<0.05$ was regarded as statistically significant. The observed genotype frequencies were compared with expected values calculated with the Hardy-Weinberg Equilibrium equation $\left(p^{2}+2 p q+q^{2}=1\right)$ by using a chi-squared test with a degree of freedom of 1 , in which $p$ represents the frequency of the wild-type allele and $q$ represents the frequency of the mutated (variant) allele. The allele frequencies of multiple genes was also calculated using Hardy-Weinberg Equilibrium equation $\left(p^{2}+q^{2}+r^{2}+2 p q+2 p r+2 q r\right)=1$, in which $p$ represents the frequency of the wild-type allele and $q$ and $r$ represent the frequency of the mutated allele.

\section{Results}

\subsection{Demographic Data and Endoscopy Results}

This study enrolled 166 patients (101 men and 65 women; mean age, $46.7 \pm 14.2$ years; range, 17-80 years). Table 1 presents the demographic data. Based on the ethnic groups, there were 14 Papuan, 27 Batak, 25 Balinese, 10 Dayak, 28 Javanese, 37 Bugis, 17 Chinese, and 8 Timorese participants. Among them, 143 (143 out of 166; 86.1\%) patients were endoscopically diagnosed with gastritis, 5 ( 5 out of $166 ; 3.0 \%$ ) patients with gastric ulcers, 1 ( 1 out of $166 ; 0.6 \%)$ patient with duodenal ulcer, and 17 (17 out of 166; 10.2\%) with gastroesophageal reflux disease (GERD).

Table 1. Demographic Data of Patients and Endoscopic Diagnosis.

\begin{tabular}{|c|c|c|c|c|c|c|c|c|c|}
\hline \multirow{2}{*}{ Ethnicity } & \multirow{2}{*}{$n$} & \multicolumn{2}{|c|}{ Age, Years } & \multicolumn{2}{|c|}{ Sex } & \multirow{2}{*}{ Gastritis } & \multirow{2}{*}{ Gastric Ulcer } & \multirow{2}{*}{ Duodenal Ulcer } & \multirow{2}{*}{ GERD * } \\
\hline & & Mean \pm SD & Range & Male & Female & & & & \\
\hline Papuan & 14 & $43.4 \pm 11.9$ & $21-63$ & 8 & 6 & $14(100)$ & $0(0.0)$ & $0(0.0)$ & $0(0.0)$ \\
\hline Batak & 27 & $51.6 \pm 16.3$ & $17-78$ & 13 & 14 & $24(88.9)$ & $2(7.4)$ & $0(0.0)$ & $1(3.7)$ \\
\hline Balinese & 25 & $46.0 \pm 12.6$ & $23-70$ & 15 & 10 & $25(100)$ & $0(0.0)$ & $0(0.0)$ & $0(0.0)$ \\
\hline Dayak & 10 & $36.8 \pm 11.8$ & $22-54$ & 5 & 5 & $9(90)$ & $0(0.0)$ & $1(10.0)$ & $0(0.0)$ \\
\hline Javanese & 28 & $42.5 \pm 11.8$ & $19-64$ & 17 & 11 & $24(85.7)$ & $1(3.6)$ & $0(0.0)$ & $3(10.7)$ \\
\hline Bugis & 37 & $47.5 \pm 14.3$ & $24-76$ & 27 & 10 & $30(81.1)$ & $2(5.4)$ & $0(0.0)$ & $5(13.5)$ \\
\hline Chinese & 17 & $46.8 \pm 14.1$ & $22-70$ & 10 & 7 & $9(52.9)$ & $0(0.0)$ & $0(0.0)$ & $8(47.1)$ \\
\hline Timorese & 8 & $61.0 \pm 12.1$ & $44-80$ & 6 & 2 & $8(100)$ & $0(0.0)$ & $0(0.0)$ & $0(0.0)$ \\
\hline
\end{tabular}

\subsection{CYP2C19 Polymorphism Genotyping}

Table 2 shows the genotyping results. For CYP2C19*2, we observed that $77(46.4 \%)$ of the 166 patients had the homozygous wild-type allele $\left({ }^{*} 1 /{ }^{*} 1\right)$; in total, $24(14.5 \%)$ had the homozygous mutated allele $\left({ }^{*} 2 /{ }^{*}\right)$; ; total of $65(39.2 \%)$ had the heterozygous allele $\left({ }^{*} 1 /{ }^{*} 2\right)$. As for the CYP2C19*3 genotyping results, we observed that 147 (88.6\%) patients had the 
homozygous wild-type allele $\left({ }^{*} 1 /{ }^{*} 1\right)$; in total, $4(2.4 \%)$ had the homozygous mutated allele $\left({ }^{*} 3 /{ }^{*} 3\right)$; a total of $15(9.0 \%)$ had the heterozygous allele $\left({ }^{*} 1 /{ }^{*}\right)$.

Table 2. CYP2C19 Polymorphism Genotyping.

\begin{tabular}{ccclcc}
\hline $\begin{array}{c}C Y P 2 \\
C 19 * 2\end{array}$ & $\begin{array}{c}C Y P 2 \\
C 19 * 3\end{array}$ & $\begin{array}{c}C Y P 2 C 19 \\
\text { Genotype }\end{array}$ & $\begin{array}{c}\text { Expected } \\
\text { Phenotype }\end{array}$ & $\boldsymbol{n}(\%)$ & $\begin{array}{c}\text { Lower-Upper } \\
\text { Proportion (95\% CI) }\end{array}$ \\
\hline${ }^{*} 1 /{ }^{*} 1$ & ${ }^{*} 1 /{ }^{*} 1$ & ${ }^{*} 1 /{ }^{*} 1$ & Rapid Metabolizer & $64(38.5)$ & $31.1-46.4$ \\
\hline${ }^{*} 1 /{ }^{*} 2$ & ${ }^{*} 1 /{ }^{*} 1$ & ${ }^{*} 1 /{ }^{*} 2$ & $\begin{array}{l}\text { Intermediate } \\
\text { Metabolizer }\end{array}$ & $60(36.1)$ & $28.8-43.9$ \\
\hline${ }^{*} 1 /{ }^{*} 1$ & ${ }^{*} 1 /{ }^{* 3}$ & ${ }^{*} 1 /{ }^{* 3}$ & $\begin{array}{l}\text { Intermediate } \\
\text { Metabolizer }\end{array}$ & $9(5.4)$ & $2.5-10.0$ \\
\hline${ }^{*} 2 /{ }^{*} 2$ & ${ }^{*} 1 /{ }^{*} 1$ & ${ }^{*} 2 /{ }^{*} 2$ & Poor Metabolizer & $23(13.9)$ & $8.9-20.0$ \\
\hline${ }^{*} 1 /{ }^{*} 1$ & ${ }^{*} 3 /{ }^{* 3}$ & ${ }^{*} 3 /{ }^{* 3}$ & Poor Metabolizer & $4(2.4)$ & $0.6-6.0$ \\
\hline${ }^{*} 2 /{ }^{*} 2$ & ${ }^{*} 1 /{ }^{* 3}$ & ${ }^{*} 2 /{ }^{* 3}$ & Poor Metabolizer & $1(0.6)$ & $0.2-3.3$ \\
\hline${ }^{*} 1 /{ }^{* 2}$ & ${ }^{*} 1 /{ }^{* 3}$ & ${ }^{*} 2 /{ }^{* 3}$ & Poor Metabolizer & $5(3.0)$ & $1.0-6.9$ \\
\hline${ }^{*}$ Estimates of the proportion were determined by the Clopper-Pearson Exact method &
\end{tabular}

In this population genetic study, we employed the Hardy-Weinberg equation to determine whether the observed genotype frequencies in the Indonesian population differed from the frequencies predicted by the equation. The $p$-value for CYP2C19*2 (representing ${ }^{*} 1$ allele) was 0.66 , and the $q$-value (representing ${ }^{*} 2$ allele) was 0.34 . As for CYP2C19*3, the $p$-value (representing ${ }^{*} 1$ allele) was 0.93 , and the $q$-value (representing ${ }^{*} 3$ allele) was 0.07 . We found that the $C Y P 2 C 19 * 2$ genetic variant conformed to the equation $\left(X^{2}=2.72\right.$, $\mathrm{P}=0.099)$, whereas the $C Y P 2 C 19 * 3$ genetic variant showed a pattern that did not fit the equation $\left(X^{2}=14.87, P<0.001\right)$, suggesting that the genotype frequency of $C Y P 2 C 19 * 3$ was not in equilibrium.

We expected that the CYP2C19 phenotype would be determined based on the combination of CYP2C19*2 and CYP2C19*3 polymorphism genotyping; we found six different allelic combinations (Table 2). In total, 64 (38.6\%) of the 166 patients were homozygous for the wild-type allele in both exon 5 and exon $4\left({ }^{*} 1 /{ }^{*} 1\right)$; overall, $36.1 \%$ (60 out of 166$)$ were heterozygous in exon $5\left({ }^{*} 1 /{ }^{*} 2\right)$; a total of $9(5.4 \%)$ were heterozygous in exon $4\left({ }^{*} 1 /{ }^{*} 3\right)$. Overall, $6(3.6 \%)$ of the 166 patients were heterozygous in exons 5 and $4(* 2 / * 3)$; a further $23(13.9 \%)$ were homozygous for the mutated allele in exon $5\left({ }^{*} 2 /{ }^{*}\right)$; a total of $4(2.4 \%)$ were homozygous for the mutated allele in exon $4(* 3 / * 3)$. We calculated that for all CYP2C19 genotypes, $59.3 \%$ (197 out of 332 ) were allele ${ }^{*} 1$; in total, $33.7 \%$ (112 out of 332 ) were allele ${ }^{*} 2$; in total, $6.9 \%$ (23 out of 332 ) were allele *3. We also employed Hardy-Weinberg equation to analyze the expected frequencies of all CYP2C19 genotypes. We found that the $p$-value (representing ${ }^{*} 1$ allele) was 0.5934 , the $q$-value (representing ${ }^{*} 2$ allele) was 0.3373 , and the $r$-value (representing *3 allele) was 0.0693; suggesting that in general, CYP2C19 did not fit to the equation $\left(X^{2}=16.91, \mathrm{P}<0.001\right)$.

The frequency of the recessive gene responsible for the decreased activity of CYP2C19 (alleles *2 and *3) was 40.7\% (135 out of 332). Overall, the prevalence of rapid, intermediate, and poor metabolizers in Indonesia was 38.5, 41.6, and 19.9\%, respectively, suggesting that more than half $(61.5 \%)$ of the participants had reduced CYP2C19 enzyme capability. In the poor metabolizer group, the frequency of allele *2 (52 out of $66 ; 78.8 \%$ ) was higher than the frequency of allele *3 (14 out of $66 ; 21.2 \%)$, suggesting that poor metabolizers of CYP2C19 in Indonesia possess a mutation predominant in exon 5 (Table 2).

\subsection{CYP2C19 Polymorphisms between Indonesian Ethnicities}

Table 3 shows the CYP2C19 genotype comparison between eight ethnic groups in Indonesia. Each ethnic group had a different distribution of CYP2C19 genotyping. Based on ethnicity, the Balinese participants had the highest prevalence for rapid metabolizers $(52.0 \%)$, followed by Javanese (46.4\%), Dayak (40\%), Bugis (37.8\%), Timorese (37.5\%), Batak 
(37.0\%), Chinese (29.4\%), and Papuan (14.3\%) participants, the ethnicity with the lowest prevalence of rapid metabolizers. Conversely, the Papuan participants had the highest prevalence of poor metabolizers $(57.1 \%)$, whereas there were no poor metabolizers in the Timorese participants. The Balinese participants had a statistically significant higher likelihood of rapid metabolizers than the Papuan (Balinese: P $=0.030$, OR 76.5, 95\% CI 1.199-35.230) (Table 4). We also found that the Papuan participants had a significantly higher likelihood of poor metabolizers than the Balinese ( $\mathrm{P}=0.002$, OR 11.0, 95\% CI 2.498-48.433) (Supplementary Table S1).

Table 3. CYP2C19 Genotype among Indonesian Ethnicities.

\begin{tabular}{|c|c|c|c|c|c|c|c|c|c|}
\hline \multirow{2}{*}{ Ethnicity } & \multicolumn{3}{|c|}{ CYP2C19*2 (\%) } & \multicolumn{3}{|c|}{ CYP2C19*3 (\%) } & \multicolumn{3}{|c|}{ CYP2C19 Genotype (\%) } \\
\hline & ${ }^{*} 1 /{ }^{*} 1$ & ${ }^{*} 1 /{ }^{*} 2$ & $* 2 / * 2$ & ${ }^{*} 1 /{ }^{*} 1$ & ${ }^{*} 1 /{ }^{*} 2$ & $* 2 / * 2$ & $\mathbf{R M}$ & IM & PM \\
\hline Papuan & $4(28.6)$ & $5(35.7)$ & $5(35.7)$ & $11(78.6)$ & $1(7.1)$ & $2(14.2)$ & $2(14.3)$ & $4(28.6)$ & $8(57.1)$ \\
\hline Batak & $14(51.9)$ & $10(37.0)$ & $3(11.1)$ & $22(81.5)$ & $5(18.5)$ & $0(0.0)$ & $10(37.0)$ & $13(48.1)$ & $4(14.8)$ \\
\hline Balinese & $13(52.0)$ & $8(32.0)$ & $4(16.0)$ & $24(96.0)$ & $1(4.0)$ & $0(0.0)$ & $13(52.0)$ & $8(32.0)$ & $4(16.0)$ \\
\hline Dayak & $5(50.0)$ & $3(30.0)$ & $2(20.0)$ & $9(90.0)$ & $1(10.0)$ & $0(0.0)$ & $4(40.0)$ & $4(40.0)$ & $2(20.0)$ \\
\hline Javanese & $16(57.1)$ & $8(28.6)$ & $4(14.3)$ & $23(82.1)$ & $4(14.3)$ & $1(3.6)$ & $13(46.4)$ & $8(28.6)$ & $7(25.0)$ \\
\hline Bugis & $15(40.5)$ & $19(51.4)$ & $3(8.1)$ & 35 (94.6) & $2(5.4)$ & $0(0.0)$ & $14(37.8)$ & $19(51.4)$ & $4(10.8)$ \\
\hline Chinese & $7(41.2)$ & $7(41.2)$ & $3(17.6)$ & $15(88.2)$ & $1(5.9)$ & $1(5.9)$ & $5(29.4)$ & $8(47.1)$ & $4(23.5)$ \\
\hline Timorese & $3(37.5)$ & $5(62.5)$ & $0(0.0)$ & $8(100)$ & $0(0.0)$ & $0(0.0)$ & $3(37.5)$ & $5(62.5)$ & $0(0.0)$ \\
\hline
\end{tabular}

$\mathrm{RM}$, rapid metabolizer; IM, intermediate metabolizer; PM, poor metabolizer.

Table 4. Association between Sex and Ethnicity and Rapid Metabolizing.

\begin{tabular}{ccccc}
\hline Characteristic & Rapid Metabolizer (\%) & OR & 95\% CI & P-Value \\
\hline Sex & & & & \\
\hline Male & $39(38.6)$ & 1.006 & $0.530-1.910$ & 0.984 \\
\hline Female & $25(38.5)$ & 1.000 & & \\
\hline Ethnicity & & & & \\
\hline Papuan & $2(14.3)$ & 1.000 & & 0.143 \\
\hline Batak & $10(37.0)$ & 3.529 & $0.652-19.099$ & $0.030 *$ \\
\hline Balinese & $13(52.0)$ & 6.500 & $1.199-35.230$ & 0.166 \\
\hline Dayak & $4(40.0)$ & 4.000 & $0.563-28.396$ & 0.053 \\
\hline Javanese & $13(44.4)$ & 5.200 & $0.978-27.653$ & 0.121 \\
\hline Bugis & $14(37.8)$ & 3.652 & $0.710-18.785$ & 0.325 \\
\hline Chinese & $5(29.4)$ & 2.500 & $0.403-15.501$ & 0.225 \\
\hline Timorese & $3(37.5)$ & 3.600 & $0.454-28.562$ & \\
\hline${ }^{*}<0.05$. & & & & \\
\hline
\end{tabular}

\subsection{CYP2C19 Polymorphisms and Clinical Outcomes}

We classified the patients into four groups of clinical outcomes based on endoscopic observation: gastritis, gastric ulcer, duodenal ulcer, and GERD. Table 5 shows the distribution of enzyme metabolizer groups based on the clinical outcomes. Among the patients with gastritis, we found that the prevalence of poor metabolizers was lower than that of rapid and intermediate metabolizers. The prevalence of poor metabolizers was also lower than that of rapid and intermediate metabolizers in GERD, although this difference was not statistically significant. There were five participants with gastric ulcers; however, none of them were included in the poor metabolizer group. There was only one participant with duodenal ulcer, and they belonged to the poor metabolizer group. 
Table 5. CYP2C19 and Clinical Outcomes Based on Endoscopy.

\begin{tabular}{|c|c|c|c|c|c|c|c|}
\hline \multirow{2}{*}{ CYP2C19 } & \multicolumn{2}{|c|}{ Gastritis } & \multicolumn{2}{|c|}{ Gastric Ulcer } & \multirow{2}{*}{\begin{tabular}{|l} 
Duodenal Ulcer \\
Proportion (\%)
\end{tabular}} & \multicolumn{2}{|c|}{ GERD } \\
\hline & Proportion (\%) & $95 \% \mathrm{CI} * *$ & Proportion (\%) & $95 \% \mathrm{CI} * *$ & & Proportion (\%) & $95 \% \mathrm{CI} * *$ \\
\hline $\mathrm{RM}$ & $55(38.5)$ & $30.4-47.0$ & $1(20.0)$ & $0.5-71.6$ & $0(0.0)$ & $8(47.1)$ & $23.0-72.2$ \\
\hline IM & $57(39.9)$ & $31.7-48.4$ & $4(80.0)$ & 28.4-99.5 & $0(0.0)$ & $8(47.1)$ & $23.0-72.2$ \\
\hline PM & $31(21.7)$ & $15.2-29.3$ & $0(0.0)$ & $0.0-52.2$ & $1(100)$ & $1(5.9)$ & \\
\hline Total & 143 & & 5 & & 1 & 17 & \\
\hline
\end{tabular}

RM, rapid metabolizer; IM, intermediate metabolizer; PM, poor metabolizer; GERD, gastroesophageal reflux disease. ${ }^{* *}$ Estimates of the proportion were determined by the Clopper-Pearson Exact method.

We also analyzed the association between the CYP2C19 metabolizer group and the histological scores based on the updated Sydney system (Supplementary Table S2). There was no significant association between neutrophil and monocyte infiltration and the metabolizer group $(\mathrm{P}>0.05)$. There was no significant association between antrum-predominant and corpus-predominant gastritis and the metabolizer group $(\mathrm{P}>0.05)$.

\section{Discussion}

CYP2C19 polymorphism is widely reported to be associated with the efficacy of acidrelated disease in the stomach due to the importance of S-mephenytoin-hydroxylase in the metabolism of various PPI drugs $[8,35,36]$. We found that, in Indonesia, intermediate metabolizers had the highest prevalence, followed by rapid metabolizers and poor metabolizers. In general, the prevalence of rapid metabolizers and poor metabolizers was 38.5 and $19.9 \%$, respectively. Our results agree with previous studies that reported a prevalence of rapid metabolizers of $65-78 \%$ for whites but only $30-40 \%$ for Asian populations, whereas the prevalence of poor metabolizers in Asian populations (13-23\%) was higher than in whites $(2-5 \%)[16,20,21,36,37]$. Although studies on CYP2C19 polymorphisms in Indonesia are still scarce, the expected genotype distribution in this study showed the same pattern as another neighboring country in Southeast Asia (Thailand) and as other Asian countries, such as Korea, Japan, and China (Supplementary Table S3).

Although the prevalence of rapid, intermediate, and poor metabolizers in Indonesia was in line with that of the neighboring country and of Asians in general, a different pattern was also observed among ethnicities. These results also support the fact that ethnicity and geography play roles in CYP2C19 polymorphism. Papuans, an ethnicity native to Papua Island, had a considerably higher prevalence of poor metabolizers than the other ethnicities, a result consistent with previous studies conducted in Papua New Guinea, a neighboring country that occupies the eastern half of the island of Papua, which reported a high prevalence of poor metabolizers [38,39]. The Papuan participants had the highest prevalence of poor metabolizers, whereas the Balinese participants had a significantly higher likelihood of having the rapid metabolizing enzyme than the Papuan. Dosage adjustment should therefore be considered for these ethnicities when administering PPIbased therapy. For rapid metabolizers, PPI-based therapy might have lower efficacy due to the faster metabolism of PPI; therefore, some patients might not respond to PPI-based therapy $[40,41]$. Increasing the PPI dosage in a population with a high prevalence of CYP2C19 rapid metabolizers might provide a benefit in maintaining adequate concentrations and effectivity of the PPI. A study in Japan showed higher eradication rates for personalized H. pylori eradication therapy among different phenotypes (rapid metabolizer, $30 \mathrm{mg}$ t.i.d.; poor metabolizer, $15 \mathrm{mg}$ b.i.d.; intermediate metabolizer, $15 \mathrm{mg}$ t.i.d.) compared with standard H. pylori eradication therapy (lansoprazole $30 \mathrm{mg}$ b.i.d.) [35]. In contrast, the same dose of pantoprazole $40 \mathrm{mg}$ in different phenotypes in South Korea had reduced efficacy in eradicating H. pylori in rapid metabolizers [36].

The prevalence of gastroduodenal disease was higher in the rapid and intermediate metabolizers than in the poor metabolizers, although the difference was not statistically significant. Our observation also showed an association between chronic pangastritis and 
intermediate metabolizers. In addition, the Papuan participants had the lowest prevalence of gastritis based on monocyte infiltration. These data support the hypothesis of the metabolizing enzyme affecting the prevalence of gastritis. Consistent with the results of a study in Thailand [16,42], more symptoms and diseases might develop due to the ineffectiveness of PPI therapy. Conversely, poor metabolizers had a slower rate of PPI metabolism, thereby increasing the peak-plasma concentration $[43,44]$ and consequently increasing the mucosal gastroprotection from nonsteroidal anti-inflammatory drugs and other drugs, leading to a lower risk of developing gastritis, peptic ulcer disease, and peptic ulcer bleeding [19].

In this study, the CYP2C19*2 polymorphism conformed to the Hardy-Weinberg Equilibrium, which can demonstrate the validity of the genetic association study because, theoretically, the population should fit within the Hardy-Weinberg Equilibrium [45]. However, the application of the Hardy-Weinberg Equilibrium as the only tool for controlling the validity of population genetic studies has been controversial [46,47]. In this study, CYP2C19*3 did not conform to the equilibrium because of the high prevalence of the wild type, a deviation that might indicate a problem due to nonrandom mating, population stratification, admixture, and selection bias, although these could not be confirmed in the current study [45,48]. Another possible reason for the population not fitting within the Hardy-Weinberg Equilibrium is the small number of samples examined, which in this case was also one of the study's limitations. Caution should therefore be taken when interpreting the results. In addition, the prevalence of rapid and poor metabolizer groups in Indonesia having a similar pattern to the CYP2C19 genotyping results in other Asian countries, such as Japan and South Korea [16,42], showed that the geographical factor might also be related to the pattern.

There are several limitations in our study. First, the small number of participants and diseases, such as gastric ulcer and duodenal ulcer. Our results might therefore be insufficient for explaining the association between the disease and CYP2C19 polymorphism. Further study is needed on CYP2C19 polymorphisms with sufficiently large sample sizes in each ethnicity and disease. Second, this study primarily described the distribution of CYP2C19 genotypes in the Indonesian population, and we did not examine the effect of the phenotypes on the treatment. Therefore, the association with the clinical outcome presented in this study served as a hypothesis that might be associated with the possible clinical effects caused by the CYP2C19 genotype variants. Third, given that there is another method for determining the phenotype, such as measuring the urinary level of $4^{\prime}$-hydroxymephenytoin [16], it would be interesting to conduct a study to deepen our understanding of the association between the CYP2C19 polymorphism and the phenotype. Fourth, this study only examined the CYP2C19*2 and CYP2C19*3 alleles and did not include $C Y P 2 C 19^{*} 17$. CYP2C19*2 and $C Y P 2 C 19 * 3$ are associated with decreasing or diminished enzyme activity, while $C Y P 2 C 19^{*} 17$ variant allele is associated with increased gene expression and increasing enzyme activity and is commonly classified as an ultrarapid metabolizer [49]. CYP2C19*2, CYP2C19*3, and CYP2C19*17 are defined as tier 1 variant alleles due to the well-characterized alteration of CYP2C19 enzyme activity [49]. Further study is needed to examine the mutation in alleles ${ }^{*} 2,{ }^{*} 3$, and ${ }^{*} 17$ to provide more accurate data in Indonesia. Currently, the clinical practice of examining CYP2C19 genotype variants is still unfeasible for use in Indonesia the limited number of facilities capable of performing the test. The results presented in this study might therefore be important for shedding light on the distribution of CYP2C19 variant alleles at the population level in Indonesia and might be used as a consideration for providing personalized treatment in clinical practice.

\section{Conclusions}

We showed that, in Indonesia, intermediate metabolizers had the highest prevalence, followed by rapid metabolizers and poor metabolizers. Dosage adjustment should be considered when administering PPI-based therapy among ethnicities in Indonesia. 
Supplementary Materials: The following are available online at https://www.mdpi.com/article/10 .3390/biology10040300/s1, Supplementary Table S1: Association between sex and ethnicity to poor metabolizer, Supplementary Table S2: Association between CYP2C19 genotype and histology scores, Supplementary Table S3: Comparison of CYP2C19 allele genotypes among various populations.

Author Contributions: Conceived and designed the experiments: D.D., M.M. and Y.Y. Performed the experiments: P.S. and D.D. Analyzed the data: M.M., D.D., P.S. and Y.Y. Contributed reagents/material/ data acquisition: A.F.S., I.A.N., L.A.W., H.M., F.A., W.B.U., G.S., K.A.F., Y.A.A.R., A.R., I.D.N.W., A.M.J.S., M.R., T.S., A.C., T.B., T.U. and Y.Y. Wrote the paper: D.D., M.M. and Y.Y. Revised the manuscript and added important content: Y.Y. All authors have read and agreed to the published version of the manuscript.

Funding: This report is based on work supported in part by grants from the National Institutes of Health (DK62813) to Y.Y. and Grants-in-Aid for Scientific Research from the Ministry of Education, Culture, Sports, Science, and Technology (MEXT) of Japan (15H02657, 16H05191, 16H06279, 18KK0266, and 19H03473) to Y.Y. This work was also supported by the Japan Society for the Promotion of Science Institutional Program for Core-to-Core Program; B. Asia-Africa Science Platform to Y.Y. This study was also funded by the Program Penelitan Kolaborasi Indonesia Grant Tahun 2021 to M.M. K.A.F. is a Ph.D. student and L.A.W. and D.D. were Ph.D. students supported by the Japanese Government (MEXT) scholarship program for 2017, 2015, and 2016, respectively.

Institutional Review Board Statement: The study protocol was approved by the Ethics Committee of Dr. Soetomo Teaching Hospital, Surabaya, Indonesia (221/Panke.KKE/IX/2012; Date: 25 September 2012), Dr. Cipto Mangunkusumo Teaching Hospital, Jakarta, Indonesia (206/112/P1/ETIK/2014; Date: 7 April 2014), Dr. Wahidin Sudirohusodo Teaching Hospital, Makassar, Indonesia (0208/H4.8.4.5.31/ PP36-KOMETIK/2015; Date: 16 February 2015), and Oita University Faculty of Medicine, Yufu, Japan (P-12-10; Date: 18 January 2013). The study's protocol followed the principles of the 2013 Declaration of Helsinki.

Informed Consent Statement: Informed consent was obtained from all subjects involved in the study.

Data Availability Statement: The data that support the findings of this study are available from the corresponding author upon reasonable request.

Conflicts of Interest: The authors declare that they have no competing interests.

\section{References}

1. Fock, K.M.; Katelaris, P.; Sugano, K.; Ang, T.L.; Hunt, R.; Talley, N.J.; Lam, S.K.; Xiao, S.D.; Tan, H.J.; Wu, C.Y.; et al. Second Asia-Pacific Consensus Guidelines for Helicobacter pylori infection. J. Gastroenterol. Hepatol. 2009, 24, 1587-1600. [CrossRef]

2. Kim, S.G.; Jung, H.K.; Lee, H.L.; Jang, J.Y.; Lee, H.; Kim, C.G.; Shin, W.G.; Shin, E.S.; Lee, Y.C. Guidelines for the diagnosis and treatment of Helicobacter pylori infection in Korea, 2013 revised edition. J. Gastroenterol. Hepatol. 2014, 29, 1371-1386. [CrossRef] [PubMed]

3. Liu, W.Z.; Xie, Y.; Cheng, H.; Lu, N.H.; Hu, F.L.; Zhang, W.D.; Zhou, L.Y.; Chen, Y.; Zeng, Z.R.; Wang, C.W.; et al. Fourth Chinese National Consensus Report on the management of Helicobacter pylori infection. J. Dig. Dis. 2013, 14, 211-221. [CrossRef] [PubMed]

4. Malfertheiner, P.; Megraud, F.; O’Morain, C.A.; Gisbert, J.P.; Kuipers, E.J.; Axon, A.T.; Bazzoli, F.; Gasbarrini, A.; Atherton, J.; Graham, D.Y.; et al. Management of Helicobacter pylori infection-the Maastricht V/Florence Consensus Report. Gut 2017, 66, 6-30. [CrossRef] [PubMed]

5. Kuipers, E.J.; Nelis, G.F.; Klinkenberg-Knol, E.C.; Snel, P.; Goldfain, D.; Kolkman, J.J.; Festen, H.P.; Dent, J.; Zeitoun, P.; Havu, N.; et al. Cure of Helicobacter pylori infection in patients with reflux oesophagitis treated with long term omeprazole reverses gastritis without exacerbation of reflux disease: Results of a randomised controlled trial. Gut 2004, 53, 12-20. [CrossRef] [PubMed]

6. Pilotto, A.; Perri, F.; Leandro, G.; Franceschi, M. Effect of Helicobacter pylori eradication on the outcome of reflux esophagitis and chronic gastritis in the elderly. A randomized, multicenter, eight-month study. Gerontology 2006, 52, 99-106. [CrossRef]

7. Schenk, B.E.; Kuipers, E.J.; Nelis, G.F.; Bloemena, E.; Thijs, J.C.; Snel, P.; Luckers, A.E.; Klinkenberg-Knol, E.C.; Festen, H.P.; Viergever, P.P.; et al. Effect of Helicobacter pylori eradication on chronic gastritis during omeprazole therapy. Gut 2000, 46, 615-621. [CrossRef]

8. Hagymasi, K.; Mullner, K.; Herszenyi, L.; Tulassay, Z. Update on the pharmacogenomics of proton pump inhibitors. Pharmacogenomics 2011, 12, 873-888. [CrossRef]

9. Kuo, C.H.; Lu, C.Y.; Shih, H.Y.; Liu, C.J.; Wu, M.C.; Hu, H.M.; Hsu, W.H.; Yu, F.J.; Wu, D.C.; Kuo, F.C. CYP2C19 polymorphism influences Helicobacter pylori eradication. World J. Gastroenterol. 2014, 20, 16029-16036. [CrossRef] 
10. Miftahussurur, M.; Syam, A.F.; Makmun, D.; Nusi, I.A.; Zein, L.H.; Zulkhairi; Akil, F.; Uswan, W.B.; Simanjuntak, D.; Uchida, T.; et al. Helicobacter pylori virulence genes in the five largest islands of Indonesia. Gut Pathog. 2015, 7, 26. [CrossRef]

11. Yang, J.C.; Lin, C.J. CYP2C19 genotypes in the pharmacokinetics/pharmacodynamics of proton pump inhibitor-based therapy of Helicobacter pylori infection. Expert. Opin. Drug. Metab. Toxicol. 2010, 6, 29-41. [CrossRef] [PubMed]

12. Zhao, F.; Wang, J.; Yang, Y.; Wang, X.; Shi, R.; Xu, Z.; Huang, Z.; Zhang, G. Effect of CYP2C19 genetic polymorphisms on the efficacy of proton pump inhibitor-based triple therapy for Helicobacter pylori eradication: A meta-analysis. Helicobacter 2008, 13, 532-541. [CrossRef]

13. Kuo, C.H.; Hsu, P.I.; Kuo, F.C.; Wang, S.S.; Hu, H.M.; Liu, C.J.; Chuah, S.K.; Chen, Y.H.; Hsieh, M.C.; Wu, D.C.; et al. Comparison of 10 day bismuth quadruple therapy with high-dose metronidazole or levofloxacin for second-line Helicobacter pylori therapy: A randomized controlled trial. J. Antimicrob. Chemother. 2013, 68, 222-228. [CrossRef] [PubMed]

14. Lin, Y.A.; Wang, H.; Gu, Z.J.; Wang, W.J.; Zeng, X.Y.; Du, Y.L.; Ying, S.S.; Zhang, B.H. Effect of CYP2C19 Gene Polymorphisms on Proton Pump Inhibitor, Amoxicillin, and Levofloxacin Triple Therapy for Eradication of Helicobacter Pylori. Med. Sci. Monit. 2017, 23, 2701-2707. [CrossRef] [PubMed]

15. Ormeci, A.; Emrence, Z.; Baran, B.; Gokturk, S.; Soyer, O.M.; Evirgen, S.; Akyuz, F.; Karaca, C.; Besisik, F.; Kaymakoglu, S.; et al. Effect of cytochrome P450 2C19 polymorphisms on the Helicobacter pylori eradication rate following two-week triple therapy with pantoprazole or rabeprazole. Eur. Rev. Med. Pharmacol. Sci. 2016, 20, 879-885.

16. Kubota, T.; Chiba, K.; Ishizaki, T. Genotyping of S-mephenytoin $4^{\prime}$-hydroxylation in an extended Japanese population. Clin. Pharmacol. Ther. 1996, 60, 661-666. [CrossRef]

17. Miyoshi, M.; Mizuno, M.; Ishiki, K.; Nagahara, Y.; Maga, T.; Torigoe, T.; Nasu, J.; Okada, H.; Yokota, K.; Oguma, K.; et al. A randomized open trial for comparison of proton pump inhibitors, omeprazole versus rabeprazole, in dual therapy for Helicobacter pylori infection in relation to CYP2C19 genetic polymorphism. J. Gastroenterol. Hepatol. 2001, 16, 723-728. [CrossRef]

18. Yamada, S.; Shiohira, H.; Yasui-Furukori, N.; Tateishi, T.; Akamine, Y.; Uno, T. The (R)-omeprazole hydroxylation index reflects CYP2C19 activity in healthy Japanese volunteers. Eur. J. Clin. Pharmacol. 2013, 69, 1423-1428. [CrossRef]

19. Jainan, W.; Vilaichone, R.K. Effects of the CYP2C19 genetic polymorphism on gastritis, peptic ulcer disease, peptic ulcer bleeding and gastric cancer. Asian Pac. J. Cancer Prev. 2014, 15, 10957-10960. [CrossRef]

20. De Morais, S.M.; Goldstein, J.A.; Xie, H.G.; Huang, S.L.; Lu, Y.Q.; Xia, H.; Xiao, Z.S.; Ile, N.; Zhou, H.H. Genetic analysis of the S-mephenytoin polymorphism in a Chinese population. Clin. Pharmacol. Ther. 1995, 58, 404-411. [CrossRef]

21. De Morais, S.M.; Wilkinson, G.R.; Blaisdell, J.; Meyer, U.A.; Nakamura, K.; Goldstein, J.A. Identification of a new genetic defect responsible for the polymorphism of (S)-mephenytoin metabolism in Japanese. Mol. Pharmacol. 1994, 46, 594-598.

22. Ferguson, R.J.; De Morais, S.M.; Benhamou, S.; Bouchardy, C.; Blaisdell, J.; Ibeanu, G.; Wilkinson, G.R.; Sarich, T.C.; Wright, J.M.; Dayer, P.; et al. A new genetic defect in human CYP2C19: Mutation of the initiation codon is responsible for poor metabolism of S-mephenytoin. J. Pharmacol. Exp. Ther. 1998, 284, 356-361.

23. Ozdil, B.; Akkiz, H.; Bayram, S.; Bekar, A.; Akgollu, E.; Sandikci, M. Influence of CYP2C19 functional polymorphism on Helicobacter pylori eradication. Turk. J. Gastroenterol. 2010, 21, 23-28. [CrossRef] [PubMed]

24. Settin, A.; Abdalla, A.F.; Al-Hussaini, A.S.; El-Baz, R.; Galal, A. Cure rate of Helicobacter pylori infection in Egyptian children related to CYP2C19 gene polymorphism. Indian J. Gastroenterol. 2014, 33, 330-335. [CrossRef] [PubMed]

25. Hicks, J.K.; Bishop, J.R.; Sangkuhl, K.; Muller, D.J.; Ji, Y.; Leckband, S.G.; Leeder, J.S.; Graham, R.L.; Chiulli, D.L.; LLerena, A.; et al. Clinical Pharmacogenetics Implementation Consortium (CPIC) Guideline for CYP2D6 and CYP2C19 Genotypes and Dosing of Selective Serotonin Reuptake Inhibitors. Clin. Pharmacol. Ther. 2015, 98, 127-134. [CrossRef]

26. Hicks, J.K.; Sangkuhl, K.; Swen, J.J.; Ellingrod, V.L.; Muller, D.J.; Shimoda, K.; Bishop, J.R.; Kharasch, E.D.; Skaar, T.C.; Gaedigk, A.; et al. Clinical pharmacogenetics implementation consortium guideline (CPIC) for CYP2D6 and CYP2C19 genotypes and dosing of tricyclic antidepressants: 2016 update. Clin. Pharmacol. Ther. 2016. [CrossRef]

27. Hicks, J.K.; Swen, J.J.; Thorn, C.F.; Sangkuhl, K.; Kharasch, E.D.; Ellingrod, V.L.; Skaar, T.C.; Muller, D.J.; Gaedigk, A.; Stingl, J.C. Clinical Pharmacogenetics Implementation Consortium guideline for CYP2D6 and CYP2C19 genotypes and dosing of tricyclic antidepressants. Clin. Pharmacol. Ther. 2013, 93, 402-408. [CrossRef]

28. Scott, S.A.; Sangkuhl, K.; Stein, C.M.; Hulot, J.S.; Mega, J.L.; Roden, D.M.; Klein, T.E.; Sabatine, M.S.; Johnson, J.A.; Shuldiner, A.R. Clinical Pharmacogenetics Implementation Consortium guidelines for CYP2C19 genotype and clopidogrel therapy: 2013 update. Clin. Pharmacol. Ther. 2013, 94, 317-323. [CrossRef]

29. Ikawati, Z.; Askitosari, T.D.; Hakim, L.; Tucci, J.; Mitchell, J. Allele frequency distributions of the drug metabolizer genes CYP2C9* 2, CYP2C9*3, and CYP2C19* 17 in the Buginese population of Indonesia. Curr. Pharm. Pers. Med. (Former. Curr. Pharm.) 2014, 12, 236-239. [CrossRef]

30. Makmun, D. Present status of endoscopy, therapeutic endoscopy and the endoscopy training system in Indonesia. Dig. Endosc. 2014, 26 (Suppl. 2), 2-9. [CrossRef]

31. Miftahussurur, M.; Waskito, L.A.; El-Serag, H.B.; Ajami, N.J.; Nusi, I.A.; Syam, A.F.; Matsumoto, T.; Rezkitha, Y.A.A.; Doohan, D.; Fauzia, K.A.; et al. Gastric microbiota and Helicobacter pylori in Indonesian population. Helicobacter 2020, 25, e12695. [CrossRef]

32. Dixon, M.F.; Genta, R.M.; Yardley, J.H.; Correa, P. Classification and grading of gastritis: The updated Sydney system. Am. J. Surg. Pathol. 1996, 20, 1161-1181. [CrossRef] [PubMed] 
33. Capurso, G.; Lahner, E.; Marcheggiano, A.; Caruana, P.; Carnuccio, A.; Bordi, C.; Delle Fave, G.; Annibale, B. Involvement of the corporal mucosa and related changes in gastric acid secretion characterize patients with iron deficiency anaemia associated with Helicobacter pylori infection. Aliment. Pharmacol. Ther. 2001, 15, 1753-1761. [CrossRef] [PubMed]

34. De Morais, S.M.; Wilkinson, G.R.; Blaisdell, J.; Nakamura, K.; Meyer, U.A.; Goldstein, J.A. The major genetic defect responsible for the polymorphism of S-mephenytoin metabolism in humans. J. Biol. Chem. 1994, 269, 15419-15422. [CrossRef]

35. Furuta, T.; Shirai, N.; Kodaira, M.; Sugimoto, M.; Nogaki, A.; Kuriyama, S.; Iwaizumi, M.; Yamade, M.; Terakawa, I.; Ohashi, K.; et al. Pharmacogenomics-based tailored versus standard therapeutic regimen for eradication of H. pylori. Clin. Pharmacol. Ther. 2007, 81, 521-528. [CrossRef] [PubMed]

36. Oh, J.H.; Dong, M.S.; Choi, M.G.; Yoo, H.W.; Lee, S.B.; Park, Y.I.; Chung, I.S. Effects of CYP2C19 and MDR1 genotype on the eradication rate of Helicobacter pylori infection by triple therapy with pantoprazole, amoxycillin and clarithromycin. J. Gastroenterol. Hepatol. 2009, 24, 294-298. [CrossRef] [PubMed]

37. Ang, G.Y.; Yu, C.Y.; Subramaniam, V.; Abdul Khalid, M.I.; Tuan Abdu Aziz, T.A.; Johari James, R.; Ahmad, A.; Abdul Rahman, T.; Mohd Nor, F.; Ismail, A.I.; et al. Detection of CYP2C19 Genetic Variants in Malaysian Orang Asli from Massively Parallel Sequencing Data. PLoS ONE 2016, 11, e0164169. [CrossRef]

38. Hsu, H.L.; Woad, K.J.; Woodfield, D.G.; Helsby, N.A. A high incidence of polymorphic CYP2C19 variants in archival blood samples from Papua New Guinea. Hum. Genom. 2008, 3, 17-23. [CrossRef]

39. Masta, A.; Lum, J.K.; Tsukahara, T.; Hwaihwanje, I.; Kaneko, A.; Paniu, M.M.; Sapuri, M.; Takahashi, N.; Ishizaki, T.; Kobayakawa, T.; et al. Analysis of Sepik populations of Papua New Guinea suggests an increase of CYP2C19 null allele frequencies during the colonization of Melanesia. Pharmacogenetics 2003, 13, 697-700. [CrossRef]

40. Park, S.; Hyun, Y.J.; Kim, Y.R.; Lee, J.H.; Ryu, S.; Kim, J.M.; Oh, W.Y.; Na, H.S.; Lee, J.G.; Seo, D.W.; et al. Effects of CYP2C19 Genetic Polymorphisms on PK/PD Responses of Omeprazole in Korean Healthy Volunteers. J. Korean Med. Sci. 2017, 32, 729-736. [CrossRef]

41. Deshpande, N.; Sharanya, V.; Kanth, R.; Murthy, H.V.V.; Sasikala, M.; Banerjee, R.; Tandan, M.; Reddy, N. Rapid and ultra-rapid metabolizers with CYP2C19*17 polymorphism do not respond to standard therapy with proton pump inhibitors. Meta Gene 2016, 9, 159-164. [CrossRef]

42. Lee, J.H.; Jung, H.Y.; Choi, K.D.; Song, H.J.; Lee, G.H.; Kim, J.H. The Influence of CYP2C19 Polymorphism on Eradication of Helicobacter pylori: A Prospective Randomized Study of Lansoprazole and Rabeprazole. Gut Liver 2010, 4, 201-206. [CrossRef]

43. Lou, H.Y.; Chang, C.C.; Sheu, M.T.; Chen, Y.C.; Ho, H.O. Optimal dose regimens of esomeprazole for gastric acid suppression with minimal influence of the CYP2C19 polymorphism. Eur. J. Clin. Pharmacol. 2009, 65, 55-64. [CrossRef] [PubMed]

44. Sugimoto, M.; Furuta, T.; Shirai, N.; Nakamura, A.; Xiao, F.; Kajimura, M.; Sugimura, H.; Hishida, A. Different effects of polymorphisms of tumor necrosis factor-alpha and interleukin-1 beta on development of peptic ulcer and gastric cancer. J. Gastroenterol. Hepatol. 2007, 22, 51-59. [CrossRef] [PubMed]

45. Lunetta, K.L. Genetic association studies. Circulation 2008, 118, 96-101. [CrossRef] [PubMed]

46. Singh, S.K. Re: Association of polymorphism in cytochrome P450 2C9 with susceptibility to head and neck cancer and treatment outcome: Pragmatic use of Hardy-Weinberg equilibrium and statistical interaction analysis. Appl. Transl. Genom. 2014, 3, 48-49. [CrossRef]

47. Shoemaker, J.; Painter, I.; Weir, B. A Bayesian characterization of Hardy-Weinberg disequilibrium. Genetics 1998, 149, 2079-2088.

48. Yong Zou, G.; Donner, A. The Merits of Testing Hardy-Weinberg Equilibrium in the Analysis of Unmatched Case-Control Data: A Cautionary Note. Ann. Hum. Genet. 2006, 70, 923-933. [CrossRef]

49. Pratt, V.M.; Del Tredici, A.L.; Hachad, H.; Ji, Y.; Kalman, L.V.; Scott, S.A.; Weck, K.E. Recommendations for Clinical CYP2C19 Genotyping Allele Selection: A Report of the Association for Molecular Pathology. J. Mol. Diagn. 2018, 20, 269-276. [CrossRef] 